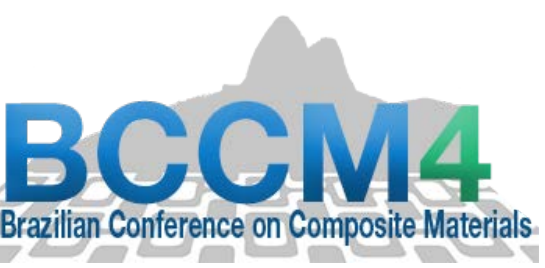

\title{
EVALUATION OF THE THERMAL PERFORMANCE OF GYPSUM COMPOSITES REINFORCED WITH SISAL FIBERS
}

\author{
Carolina Del P.C. Pinto ${ }^{(1)}$, Alana S. Cunha ${ }^{(2)}$ and Ricardo F. Carvalho( ${ }^{(3)}$
}

(1) Postgraduate Program in Civil Engineering. Department of Construction and Structure. Federal University of Bahia, Salvador, Bahia, Brazil.

(2) Graduating Program in Civil Engineering. Department of Construction and Structure. Federal University of Bahia, Salvador, Bahia, Brazil.

(3) Full Professor. Department of Construction and Structure. Federal University of Bahia, Department of Construction and Structure. Federal University of Bahia, Salvador, Bahia, Brazil.

https://doi.org/10.21452/bccm4.2018.10.03

\begin{abstract}
New housing needs and constructive demands required new constructive solutions based on the use of innovative materials, aiming at energy efficiency of solutions, reducing waste, maintains of buildings and pollutants such as $\mathrm{CO}_{2}$. The composites materials with a ceramic matrix and fibres as reinforcement originate materials widely used in building industry. However, the study of the thermal properties of these composites materials with ceramic matrix contributes to the determination of the conditions of use as thermal insulation providing the distribution of temperatures and thermal comfort of the built space. This study describes the experiments performed to characterize a thermal insulation material to determine the specific heat, resistance, transmittance and thermal delay of the gypsum composite reinforced with sisal nonwoven. The objective of this work is to make a comparative evaluation of the thermal performance, using gypsum (highly porous and without reinforcement) and a gypsum matrix composite material and sisal nonwoven ("in natura") as reinforcement phase. Among the composites used in this study are the following conformations: gypsum-sisal-gypsum (GMG), gypsum-sisal-sisal-gypsum (GMMG), gypsum-sisal-gypsum-sisal-gypsum (GMGMG). Specific heat, resistance, transmittance, and thermal delay tests are performed. The results shows that sisal fibres increase the thermal performance of the standard gypsum, increasing the specific heat of the material, the resistance and the thermal delay, reducing thermal transmittance and improving the thermal insulation function of the material.
\end{abstract}




\section{INTRODUCTION}

Currently, the construction industry faces an environmental crisis of various dimensions, since buildings are considered a cause of contamination. Conventional materials used as thermal insulation in civil construction are characterized by the high generation of waste, high energy consumption, and the generation of $\mathrm{CO} 2$, making it fundamental to reduce it [1]

It is fundamental to create new solutions for construction that achieve energy efficiency and environmentally friendly, from innovative materials such as composites that contribute to advances in civil construction, helping the evolution of conventional insulating materials.

The composite materials allow combining the properties of two or more materials in order to improve the physical, mechanical, thermal and acoustic properties. Conformed by a matrix phase and the reinforcing phase, the matrix acts as an envelope that will protect the reinforcement. Contrarily, the reinforcement will provide the matrix with greater resistance.

Currently there is an interest in the development of composites reinforced by natural fibers, presenting advantages such as lightness, renewable font, esthetics, ease handling, maintenance and versatility, which generate different investigations on the use and behavior of fibres as reinforcement for composites, in order to replace the synthetic fibres used in construction.

Sisal fibres are used as a component for the insulation material, benefiting from their flexibility, tensile strength, elasticity, density and high porosity in order to improve the thermal behaviour of the composite.

The matrix chosen was gypsum plaster. This plaster has been used in the building sector due to its physical and chemical properties, as well as for the acoustic and thermal performance, including the fire resistance. Its use has increased in building applications as panels, boards, furniture and ceiling, always as coating obviating its structural characteristic. Therefore, the blend of sisal and gypsum plaster fiber allows obtaining a light composite for use in social housing as a low cost solution, reducing the energy consumption of buildings [2]

The insulating materials must maintain the internal quality of the environment built, therefore it's crucial to analyse the thermal properties of the composite material that will the influence on its behavior, in order to meet the technical criteria for this implementation in building.

Several studies have addressed thermal behavior to demonstrate the impact of the use of fiber in gypsum matrix to achieve thermal comfort in buildings. Firstly, Li, Mai and Ye (2000) analyzed the characteristics of sisal fibers and the composites conformed by a reinforcing phase with sisal fiber and with several matrix phases such as thermoplastics, thermosets, rubber, gypsum and cement. For sisal fiber-reinforced gypsum matrices for civil construction, the importance of interfacial bonding from the spacing of the composite cracks is presented as a material for the use of lining walls and linings with good resistance to the combustion of the composite, presenting a shrinkage of the plaster with the loss of water by the high temperatures that generate cracks in the surface of the plaster, emphasizing that these cracks decrease with the use of sisal fiber.

Ornaghi [3] evaluated the thermal and kinetic degradation of plant fiber decomposition, including sisal fiber. It concludes that there are two types of fibre degradation: diffusion and random nucleation, so the thermal stability is not related to the crystallinity content but to the lignocellulosic components of the sisal fibers. Consequently, sisal fiber loses properties with increasing temperature but the higher the amount of fibers, the less the loss of their properties.

$\mathrm{Xu}$ et al. [4] concluded that the thermal conductivity of a low density binderless composite is similar as the conventional material used for insulation. As well as gypsum composite with cocoanut coir mixture fibre and composite reinforces with wood shavings and barley straw [2]

Walker and Pavia [5] analyses the performance of brick walls with seven internal solutions including cork lime and hemp lime. These seven types of wall were compared to a traditional lime plaster finish. The results presented a lower thermal transmittance of the seven types of 
wall, between 34-61\% and raising the external temperature of the wall provoking interstitial condensation of the wall. With the lime cork and hemp lime provide and 45\% and 36,9\%, respectively, improvement on the thermal transmittance. On the other hand, these types of walls present the best results for specific heat of the materials, allowing them to control the temperatures in the wall. So the thermal transmittance and the specific heat of the material need to be balanced, according to the density and thickness of the architectural solution.

Chikhi, Agoudjil, Boudense and Gherabli [2] subsequently develop a bio composite material with date palm fibers to be used as thermal insulation in buildings. The results showed that the thermal conductivity of the material decreases with the increasing of the fiber, decreasing the thermal transmittance with values close to the conventional insulating materials used in construction. Therefore the quantity of fiber used in the composition of the composite will improve not only the thermal performance also the mechanical properties.

The objective of this work is to make a comparative evaluation of the thermal performance, using gypsum (highly porous and without reinforcement) and a gypsum matrix composite material and sisal nonwoven "in nature" as reinforcement phase, setting a total of three composites.

\section{$2 \quad$ Materials and methods}

In this study, the sisal fibre was used as a nonwoven. It was collected in Brazil and provided by Hamilton Rios Ltd., which employs sisal from the city of Conceição do Coité Bahia. The nonwoven was formed by compression of the sisal fibers.

The gypsum plaster used in this study is coating plaster from Araripe, Pernanbuco. For the mixture of the coating plaster it was used an additive. It's a liquid superplasticizer additive, ready-to-use, presenting high fluidity and greater workability to the coating plaster, reducing the relation water-gypsum. It was made with a dosage of $1 \%$ which is mixture to the water before adding the plaster.

\subsection{Composite preparation}

The composite samples were prepared with four different compositions. The first sample was called GP and were prepared with 0,4 proportion of plaster/water and $1 \%$ of additive. The second sample was called GMG with one layer of nonwoven in the middle of the material. The third sample, called GMMG has two layers of fiber and one layer of plaster. And finally the fourth sample, called GMGMG, was made with one layer of sisal nonwoven, one of plaster, one layer of nonwoven and a final layer. Material control was performed in weight.

\subsection{Thermal properties}

\subsubsection{Specific heat}

Specific heat tests were conducted according to ASTM C 351 - 92b, NBR 15575, NBR 15220 and its supplementary standards, which investigate the amount of energy released by the mass of the sample. The composite were dried at $80^{\circ} \mathrm{C}$ until constant weight e temperature before specific heat experiments.

The values for the specific heat were calculated using the following formula: $\mathrm{Cp}=\mathrm{Q} /(\mathrm{m} \Delta \mathrm{t})$

Where $\mathrm{Q}$ is the heat flow $(\mathrm{J}), \mathrm{m}$ is the mass of the sample $(\mathrm{kg})$ and $\Delta \mathrm{t}$ which is the difference between the temperature of the sample and de temperature of the water (K). 


\subsubsection{Thermal resistance}

Thermal resistance tests were carried out according to NBR 15575 and NBR 15220 which investigate the capacity of the material to resist the passage of heat.

The values for the specific heat was calculated using the following formula: $\mathrm{R}=\mathrm{e} / \lambda$

Where e is the thickness of the sample $(\mathrm{m})$ and $\lambda$ is the thermal conductivity of the sample $(\mathrm{W} / \mathrm{mK})$.

\subsubsection{Thermal transmittance}

Thermal transmittance tests were carried out according to NBR 15575 and NBR 15220 which investigate the rate of heat through one square meter of the material according to the difference of temperature across of it.

The values for the specific heat were calculated using the following formula: $\mathrm{U}=1 / \mathrm{R}$

Where $\mathrm{R}$ is the thermal resistance of the sample $\left(\left(\mathrm{m}^{3} \mathrm{~K}\right) / \mathrm{W}\right)$.

\subsubsection{Thermal delay}

Thermal delay tests were conducted according to NBR 15575 and NBR 15220 and its supplementary standards which investigate the time elapsed between a thermal variation in the surface of a material and its manifestation on the opposite surface. The material is subjected to a periodic heat transmission.

The values for thermal delay in homogeneous samples were calculated using the following formula:

$\varphi=0,7284 \sqrt{ } \mathrm{R}_{\mathrm{t}}+\mathrm{C}_{\mathrm{t}}$

Where $\varphi$ is the thermal delay $(\mathrm{h}), \mathrm{Ct}$ the heat capacity of the sample $(\mathrm{J} / \mathrm{K})$ and $\mathrm{Rt}$ is the thermal resistance of the sample $\left(\left(\mathrm{m}^{3} \mathrm{~K}\right) / \mathrm{W}\right)$.

The values for thermal delay in heterogeneous samples were calculated using the following formula:

$\varphi=1,382 \mathrm{R} \sqrt{ } \mathrm{B}_{1}+\mathrm{B}_{2}$

$B_{1}=0,226 \frac{B_{0}}{R_{t}}$

$B_{2}=0,205\left(\frac{(\lambda \rho c) e x t}{R t}\right)\left(\operatorname{Re} x t-\frac{R t-\operatorname{Re} x t}{10}\right)$

$\mathrm{Bo}=\mathrm{Ct}-\mathrm{Ct}$ ext

Where, $\varphi$ is the thermal delay, (h) $\lambda$ is the thermal conductivity of the composite $(\mathrm{W} / \mathrm{mK})$, $\mathrm{p}$ is the density of the sample $\left(\mathrm{kg} / \mathrm{m}^{3}\right), \mathrm{C}_{\mathrm{t}}$ is the heat capacity of the sample $(\mathrm{J} / \mathrm{K}), \mathrm{C}_{\mathrm{t}}$ ext is the heat capacity of the external layer of the sample $(\mathrm{J} / \mathrm{K}), \mathrm{R}_{\mathrm{t}}$ is the thermal resistance of the sample $\left(\left(\mathrm{m}^{3} \mathrm{~K}\right) / \mathrm{W}\right)$, e is the thickness of the sample and Rext of the external layer of the sample $\left(\left(\mathrm{m}^{3} \mathrm{~K}\right) / \mathrm{W}\right)$.

\subsubsection{Heat capacity}

Heat capacity test were carried out according to NBR 15575 and NBR 15220 and its supplementary standards which investigate the amount of heat needed to vary the temperature of the material.

The values for thermal delay in heterogeneous samples were calculated using the following formula: 


$$
C t=\sum_{i=1}^{n} \lambda_{i} R_{i} c_{i} \rho_{i}=\sum_{i=1}^{n} e_{i} c_{i} \rho_{i}
$$

Where $\mathrm{Ct}$ is the heat capacity of the sample $(\mathrm{J} / \mathrm{K}), \lambda_{\mathrm{i}}$ is the thermal conductivity of the layer of the sample $(\mathrm{W} / \mathrm{mK})$, pi is the density of the layer of the sample $(\mathrm{kg} / \mathrm{m} 3), \mathrm{C}_{\mathrm{i}}$ is the specific heat of the layer of the sample $\mathrm{J} /(\mathrm{kgK})$, $\mathrm{Ri}$ is the thermal resistance of the layer of the sample $((\mathrm{m} 3 \mathrm{~K}) / \mathrm{W})$ and $\mathrm{e}$ is the thickness of the layer.

\section{RESULTS AND DISCUSSIONS}

\subsection{Specific heat}

Specific heat of the composite is an important parameter mainly when natural fibre is applied. Fig. 1 presents the specific heat capacity of the gypsum (GP) and the three types of composite developed (GMG, GMMG and GMGMG)

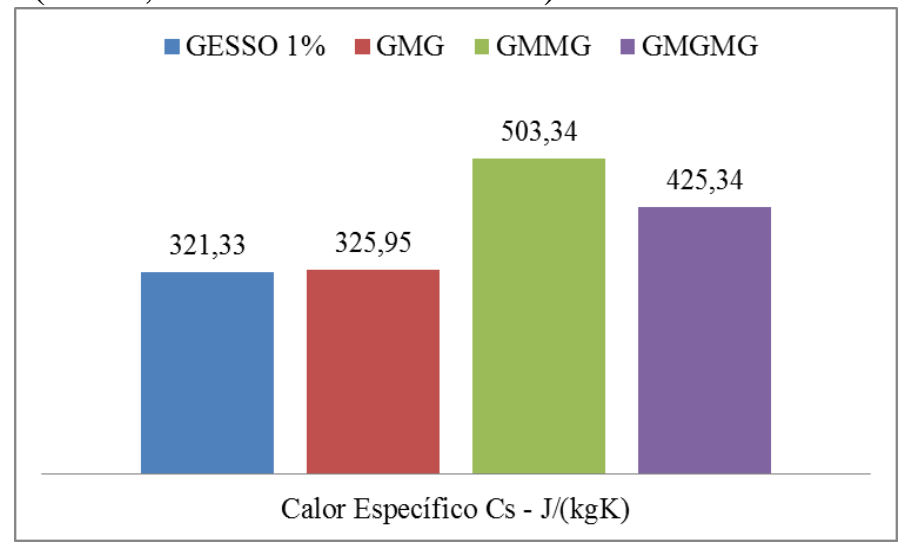

Figure 2: Specific heat values of the gypsum and the gypsum reinforced with sisal nonwoven composites.

We can clearly see that the increase of the fibres content induces a higher saturation time, reaching a temperature balance of $34,3^{\circ} \mathrm{C}$ at $14 \mathrm{~min}, 15 \mathrm{~min}, 22 \mathrm{~min}$, after $25 \mathrm{~min}$. minutes for the GP, GMG, GMMG and GMGMG, respectively.

In Fig. 2 and 3 we notice that the heat exchange is important in the beginning of the process, occurring rapidly and allowing the increasing of the temperature in $27,27 \%$, for the GP. However the evolution in the increasing of temperature in the composites is more significant than the GP with an increase of $26,89 \%, 32.52 \%$ and $45,16 \%$, for the GMG, GMMG and GMGMG, respectively. However, after time, the heat exchange rate slows down until reaching the point of equilibrium. The velocity of the heat transfer in composites is related to the filling of the voids presented in the fibres, as well as the capacity of the fibres to absorb the heat without realising it. 


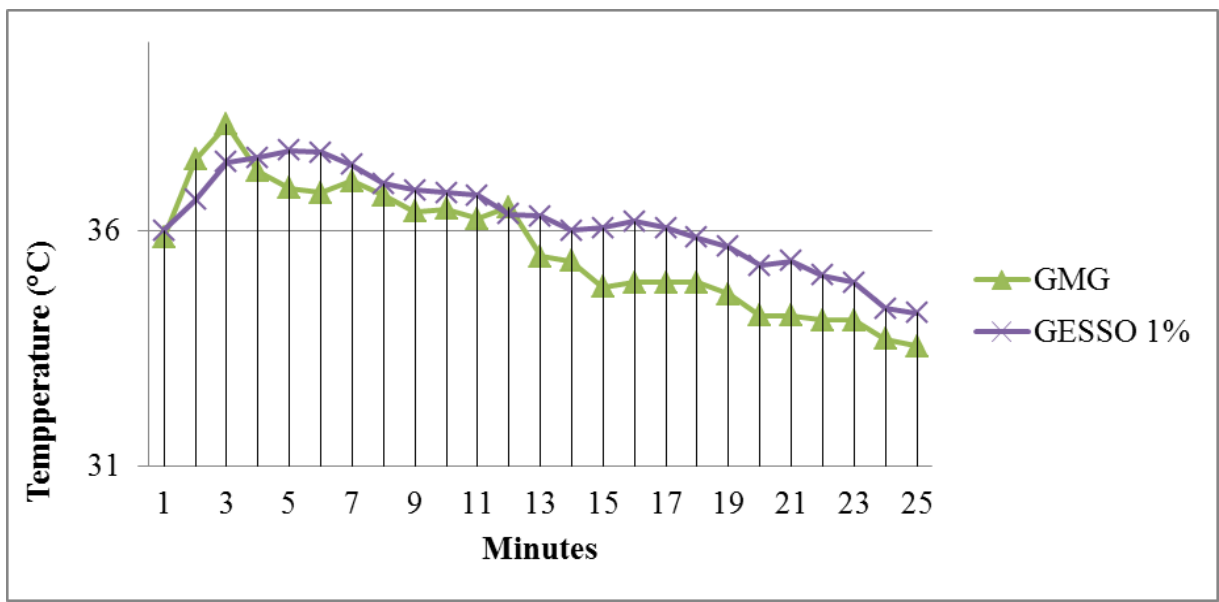

Figure 2: Heat exchange of the samples GP and GMG.

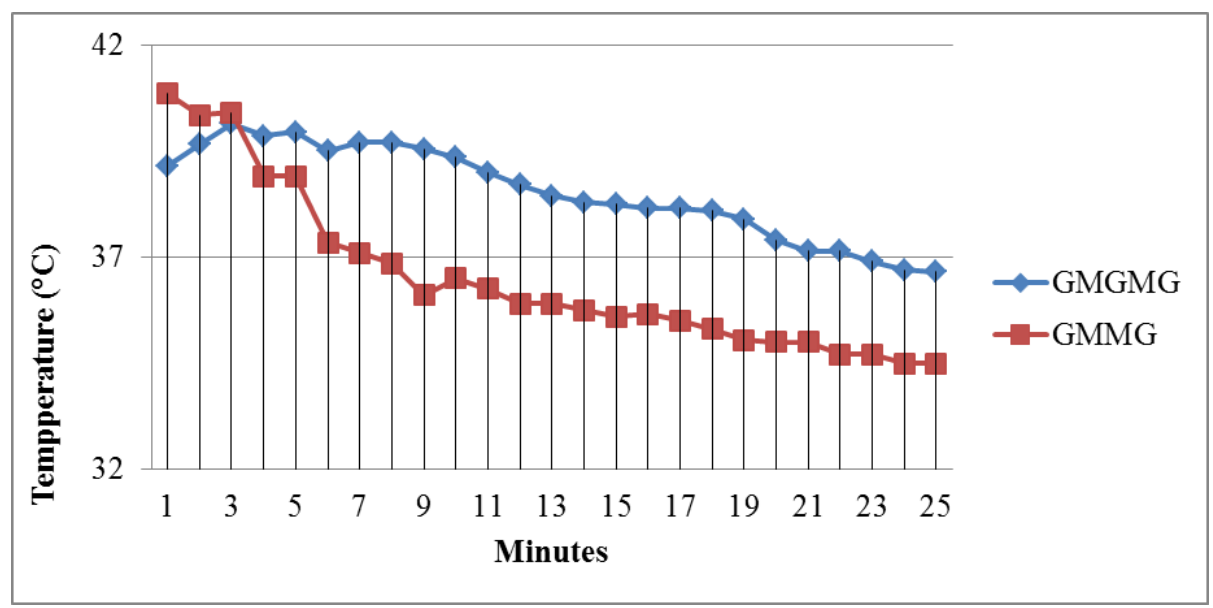

Figure 3: Heat exchange of the samples GMMG and GMGMG.

\subsection{Thermal resistance}

The thermal resistance measured for the GP is $0.02 \mathrm{~m} 3 \mathrm{~K} / \mathrm{W}$, compared to the GMG composite with $0.036 \mathrm{~m} 3 \mathrm{~K} / \mathrm{W}$. Also in table 1 we notice the values for GMMG with 0.076 $\mathrm{m} 3 \mathrm{~K} / \mathrm{W}$ and GMGMG with $0.095 \mathrm{~m} 3 \mathrm{~K} / \mathrm{W}$. Therefore, the amount of fibres increased in the conformation of the composite allows us to improve the performance of the composite and retarding the trespassing of the heat flow inside the material. This could be related to the specific heat of each sample, for example, the GMMG composite is the material that presents the biggest values of specific heat and also the second best values for thermal resistance, next to GMGMG.

Table 1. Thermal properties values for the materials. 
$4^{\text {th }}$ Brazilian Conference on Composite Materials. Rio de Janeiro, July $22^{\text {nd }}-25^{\text {th }}, 2018$

\begin{tabular}{ccccccc}
\hline Material & $\begin{array}{c}\text { Specific } \\
\text { Mass } \\
\mathrm{g} / \mathrm{cm}^{3}\end{array}$ & $\begin{array}{c}\text { Fibre } \\
\text { content } \\
\%\end{array}$ & $\begin{array}{c}\text { Thermal } \\
\text { Resistance } \\
\mathrm{m}^{2} \mathrm{~K} / \mathrm{W}\end{array}$ & $\begin{array}{c}\text { Thermal } \\
\text { transmittance } \\
\mathrm{W} / / \mathrm{m}^{2} \mathrm{~K}\end{array}$ & $\begin{array}{c}\text { Thermal } \\
\text { delay } \\
\mathrm{h}\end{array}$ & $\begin{array}{c}\text { Heat } \\
\text { capacity } \\
\mathrm{KJ} / \mathrm{m}^{2} \mathrm{~K}\end{array}$ \\
\hline GP & 157.051 & 0 & 0.020 & 48.06 & 91.4 & 756.99 \\
GMG & 131.944 & 0.84 & 0.036 & 27.61 & 93.64 & 645.10 \\
GMMG & 97.115 & 2.29 & 0.076 & 13.17 & 193.08 & 1222.06 \\
GMGMG & 110.576 & 2.019 & 0.095 & 10.46 & 234.08 & 1410.97 \\
\hline
\end{tabular}

Thermal resistance is a properties that is related to the thickness of the material, GP and GMG are materials that have the same thickness, on the other hand GMMG and GMGMG presents a bigger thickness which also improve the thermal resistance of the material, without forgetting that they are the composites with more quantity of fibres in the composition.

\subsection{Thermal transmittance}

The samples revealed that the increasing of the fibres in the gypsum decreases the heat transfer in the plaster. As shown in table 1, the amount of heat flow radiated through the material decreases according with the amount of fibre of the composite. The thermal transmittance of the GP is $48.06 \mathrm{~W} /(\mathrm{m} 2 \mathrm{~K})$, GMG is $27.61 \mathrm{~W} /(\mathrm{m} 2 \mathrm{~K})$, GMMG is 13.71 $\mathrm{W} /(\mathrm{m} 2 \mathrm{~K})$ and GMGMG $10.46 \mathrm{~W} /(\mathrm{m} 2 \mathrm{~K})$, which represents the $20.45 \%, 35.89 \%$ and $37.6 \%$ of the values for GP, respectively.

\subsection{Thermal delay}

The thermal delay of the material is related to the composition of the composites in layers, defining the material as a homogenous or heterogeneous. As shown in table 1, for the homogenous material, GP, the heat flux crosses the material in $91.41 \mathrm{hrs}$. In heterogeneous materials, GMG, GMMG and GMGMG, the values obtained are 93.64hrs, 193.08hrs and $234.08 \mathrm{hrs}$, respectively. Therefore, the composition of the layer will define the performance of the composite and its efficiency.

\subsection{Heat capacity}

The heat capacity of the materials is related to the density and thickness of the materials, therefore the composites with more layers and more quantity of gypsum shows higher values. Table 1 demonstrate that de GMGMG has the higher values followed by GMMG, GMG and GP, with $1410.97 \mathrm{KJ} / \mathrm{m} 2 \mathrm{~K}, 12222.06 \mathrm{KJ} / \mathrm{m} 2 \mathrm{~K}, 645.10 \mathrm{KJ} / \mathrm{m} 2 \mathrm{~K}, 756.99 \mathrm{KJ} / \mathrm{m} 2 \mathrm{~K}$, respectively.

\section{CONCLUSIONS}

- The specific heat of the composites are related with the amount of fibre of the composite, the quantity of voids of the sisal nonwoven and the type and quality of gypsum used for the conformation of the composite. These elements will interfere with the adherence between the nonwoven of sisal and the gypsum, which will be related to the specific heat, thermal transmittance and resistance.

- The thermal transmittance, thermal resistance and thermal delay are related with the barriers that the layers of the composite create so the heat flux will not cross the material easily. Also, in the heterogonous composite GMGMG the thermal delay increases because of the different types of materials that the heat flux must cross which is more difficult than the GMMG composite 
- The heat capacity of the materials analysed shows the importance of the density of the nonwoven used in the conformation of the layers for each composite and the importance of the thickness of the layer made with gypsum that must be precise so it can be evaluated in the same condition each composite.

\section{ACKNOWLEDGEMENTS}

The authors would like to thank CAPES, Coordination of Improvement of Higher Level People, for their support and help through this work. The authors wish to express their gratitude to BASF and all the laboratories that provided the materials to develop this study.

\section{REFERENCES}

[1] Cherki, A.; Remy, B.; Khabbazi, A.; Jannot, Y.; Baillis, D. Experimental thermal properties characterization of insulating cork-gypsum composite. Construction and buildings materials. 2014. p.8. doi:10.1016/j.conbuildmat.2013.12.076

[2] Chikki, M.; Agoudjil, B.; Boudenne, A. and Gherabli, A. Experimental investigation of new biocomposite with low cost for thermal insulation. Energy and buildings. 2013. P.7. http://dx.doi.org/10.1016/j.enbuild.2013.07.019

[3] ORNAGHI, H.L.J. Thermal behaviour of vegetables fibres and dynamic-mechanical properties of polymeric sisal fiber composites. 2014. P. Dissertation (Doctorate in Mining, Metallurgical and Materials Engineering). Federal University of Rio Grande do Sul, Porto Alegre.

[4] Xu, J.Y; Widyorini, R.; Han, G.P. and Kawai, S. Manufacture and properties of low density binderless particleboard from kenaf core. Journal of Wood Science 50. 2004. p.62-67. https://doi-org.ez10.periodicos.capes.gov.br/10.1007/s10086-003-0522-1

[5] Walker, R. and Pavia, S. Thermal performance of a selection of insulation materials suitable for historic buildings. Building and Environment. $2015 . \quad$ p.6. https://doi.org/10.1016/j.buildenv.2015.07.033 